\title{
Cerebral Metabolic Responses of Hyperglycemic Immature Rats to Hypoxia-Ischemia
}

\author{
ROBERT C. VANNUCCI, FRANCESCA VASTA, AND SUSAN J. VANNUCCI \\ Department of Pediatrics (Pediatric Neurology), The Milton S. Hershey Medical Center of The Pennsylvania
} State University, Hershey, Pennsylvania 17033

\begin{abstract}
Unlike adult rats, glucose supplementation of immature rats does not lead to accentuated hypoxicischemic brain damage. To explore the reason for this agespecific paradox, we subjected 7-day postnatal rats to unilateral common carotid artery occlusion followed by a subcutaneous injection of either $0.1 \mathrm{ml} 50 \%$ glucose or normal saline. They were then exposed to hypoxia with $8 \%$ oxygen, during which they received $2.5 \mu \mathrm{Ci} 2-\left[{ }^{14} \mathrm{C}\right]-$ glucose or were quick-frozen for brain metabolite analysis. During hypoxia-ischemia, glucose transport into the ipsilateral cerebral hemisphere of the hyperglycemic rats was greater $(+100-150 \%)$ than in normoglycemic animals. However, glucose consumption was similar in the two groups. Glucose concentrations in brain were lower during hypoxia-ischemia in the normoglycemic animals, whereas lactate increased to similar levels in the two groups. The high-energy phosphate reserves, ATP and phosphocreatine, were depleted to a similar extent. Thus, hyperglycemia combined with hypoxia-ischemia, although associated with increased glucose transport into brain, does not lead to enhanced glucose utilization or lactate accumulation by brain over that of hypoxia-ischemia alone. (Pediatr Res 21: 524-529, 1987)
\end{abstract}

Abbreviation

PCA, perchloric acid

It is unclear whether elevated blood glucose concentrations are protective or damaging to the human brain during perinatal hypoxia-ischemia. This is an important question, since glucose infusions ranging in concentrations from 5 to $25 \%$ are administered frequently to premature and distressed full-term newborn infants. Furthermore, blood glucose concentrations can be quite variable in newborn infants, with levels occasionally exceeding $500 \mathrm{mg} / \mathrm{dl}(1,2)$. Based on data in experimental animals, many physicians believe that even modestly high blood glucose concentrations are beneficial to the newborn infant undergoing hypoxic stress (3). In this regard, Himwich et al. (4) found that immature rats pretreated with glucose and then rendered anoxic survive twice as long as untreated controls (see also Refs. 5-8). The mechanism of this glucose protection presumably relates to increased endogenous carbohydrate stores (glucose and glycogen)

Received September 15, 1986; accepted December 24, 1986.

All correspondence and reprint requests to Robert C. Vannucci, M.D., Department of Pediatrics, The Milton S. Hershey Medical Center, P.O. Box 850, Hershey PA 17033.

Supported by Grant 15738 from The National Institute of Child Health and Human Development and by a grant from the American Diabetes Association. in brain and heart sufficient to maintain blood and tissue glucose levels for an extended interval during a hypoxic or anoxic insult $(6,7,9,10)$.

Despite the heightened hypoxic resistance of glucose supplemented perinatal animals, recent experiments have shown that glucose can be damaging to the brain during hypoxia-ischemia. Myers and Yamaguchi (11) found that food-deprived juvenile monkeys recover relatively undamaged after a 10 - to $14-\mathrm{min}$ cardiorespiratory arrest, whereas fed or glucose pretreated monkeys show clinical signs of elevated intracranial pressure followed by death. These investigators compared the brain pathology of the glucose supplemented and fasted monkeys subjected to cerebral hypoxia-ischemia and found more extensive damage in the glucose-treated animals. Other investigators have reported similar data for adult animals of other species $(12,13)$. Thus, glucose appears to have a paradoxical role in hypoxia-ischemia; prolonging hypoxic survival of immature animals on the one hand, while increasing brain damage in adult animals on the other.

To resolve the age-specific paradox regarding the influence of glucose on cerebral hypoxia-ischemia, we devised a series of experiments in an immature rat model of hypoxic-ischemic brain damage previously developed in our laboratory (14). In the initial investigation, we compared the extent of brain damage in glucose pretreated and control 7-day postnatal rats subjected to unilateral common carotid artery occlusion followed by $2 \mathrm{~h}$ of hypoxia (8). Gross and microscopic examination of the brains revealed no discernable difference in either the nature or extent of damage in the two groups. From this experiment, we concluded that, unlike the adult, glucose supplementation and its associated hyperglycemia in the immature rat does not increase the extent of hypoxic-ischemic brain damage.

In the experiments reported herein, we focused on biochemical responses of immature rat brain to hypoxia-ischemia with and without glucose supplementation. The findings are discussed in light of current knowledge regarding biochemical mechanisms responsible for the brain damaging effects of glucose in adult animals.

\section{MATERIALS AND METHODS}

Seven-day postnatal Wistar rats, reared with their dams, were lightly anesthetized with halothane, during which the right common carotid artery was permanently ligated as previously described (14). Following a 4-hr recovery period with their dams, half of the animals received a subcutaneous injection of $0.1 \mathrm{ml}$ $50 \%$ glucose; the remaining littermates received $0.1 \mathrm{ml} 0.9 \%$ $\mathrm{NaCl}$. Fifteen minutes later, pairs of glucose and saline injected rat pups were placed in $500 \mathrm{ml}$ air-tight jars partially submerged in a $37^{\circ} \mathrm{C}$ water bath, and the animals were exposed to varying durations $(0,20,60$, or $120 \mathrm{~min})$ of a humidified gas mixture 
containing $8 \% \quad 0_{2}$-balance $\mathrm{N}_{2}$. Some littermates were neither ligated, injected, nor rendered hypoxic (controls).

Within $5 \mathrm{~s}$ following cessation of hypoxia, the rat pups were decapitated, and the isolated heads quick frozen in liquid nitrogen to arrest brain metabolism. Blood samples were collected from the severed neck vessels and measured aliquots diluted 1:10 in $0.5 \mathrm{M}$ PCA for later fluorometric analysis of glucose, lactate, and pyruvate (see below). The brains were dissected free from their calvaria in a cold box at $-25^{\circ} \mathrm{C}$, and brain samples from each cerebral hemisphere (approximately $50 \mathrm{mg}$ ) were powdered, weighed and extracted into $3.0 \mathrm{M} \mathrm{PCA}$ as previously described (15).

Fluorometric assays were conducted to determine glucose, lactate, and pyruvate concentrations in blood and brain as well as phosphocreatine, ATP, ADP, and AMP in brain using standardized enzymatic techniques $(15,16)$. Enzymes were purchased from Boehringer-Manheim (Minneapolis, MN); other biochemicals were obtained from Sigma Chemical Company (St. Louis, $\mathrm{MO})$.

In additional experiments, cerebral glucose utilization was determined in immature rats, as originally described by Hawkins et al. (17) and modified by Miller and Corddry (18). Specifically, carotid artery ligated rat pups were subjected to varying durations of hypoxia, during which they received a subcutaneous injection of $2.5 \mu \mathrm{Ci}(0.2 \mathrm{ml}) 2-\left[{ }^{14} \mathrm{C}\right]$-glucose. Either $0.5,1,2,5$, or $10 \mathrm{~min}$ following the injection, the animals were removed from the hypoxia jars (see above) and immediately decapitated. The isolated heads of the animals injected 10 min previously were quickfrozen in liquid nitrogen. Blood (approximately $0.1 \mathrm{ml}$ ) was collected from the severed neck vessels of all animals into heparinized capillary tubes, centrifuged at $3,000 \times g$ for $3 \mathrm{~min}$, and a precise volume of the supernatant plasma $(0.05 \mathrm{ml})$ diluted $1: 10$ in $0.5 \mathrm{M}$ PCA. The specimen then was neutralized to $\mathrm{pH}$ 7.0 with $1.0 \mathrm{M} \mathrm{KHCO}_{3}$, and an exact aliquot $(0.1 \mathrm{ml})$ added to $10 \mathrm{ml}$ of dimilune-30 (United Technologics Packard, Downers Grove, IL). The solution then was counted in a scintillation spectrometer (Beckman, Sommerset, NJ) with appropriate standards and blanks. Another aliquot of the PCA extract was assayed for glucose concentration according to a standard fluorometric method (16). The remaining PCA extract $(0.4 \mathrm{ml})$ was passed over an ion-exchange column formate form (Biorad Econocolumn, Richmond, CA) and eluted with $3 \mathrm{ml}$ deionized water. The eluent, containing only neutral compounds (predominantly or exclusively glucose), then was isotopically counted and assayed for glucose content. From these procedures, it was ascertained that the plasma glucose-specific activity at each measured interval was not different prior to and following the chromatographic procedure, indicating that essentially $100 \%$ of the circulating isotope remained as $2-\left[{ }^{14} \mathrm{C}\right]$-glucose for up to $10 \mathrm{~min}$ of hypoxia.

Each frozen radioactive brain was removed from its skull in a cold box $\left(-25^{\circ} \mathrm{C}\right)$, the brainstem-cerebellum removed and discarded, and the forebrain bissected in the sagittal plane to separate the cerebral hemispheres. The hemispheres then were separately powdered under liquid nitrogen, weighed, and extracted into $3 \mathrm{M}$ PCA. The extracts then were neutralized to $\mathrm{pH} 7.0$ as previously described (15). As with the blood specimens, an aliquot $(0.1 \mathrm{ml})$ of the neutralized PCA extract was added to 10 $\mathrm{ml}$ of dimilune-30 and counted in a scintillation spectrometer, while another aliquot was fluorometrically assayed for glucose content. The remaining portion of the extract was passed over an ion-exchange column formate form and eluted with $3 \mathrm{ml}$ water. Aliquots of the eluent then were isotopically counted or assayed for glucose. From these procedures, the amount of ${ }^{14} \mathrm{C}$ $(\mathrm{dpm} / \mathrm{g})$ in the acid soluble metabolites in brain was determined by subtracting the ${ }^{14} \mathrm{C}$ in the neutral compounds (glucose) from the ${ }^{14} \mathrm{C}$ in the total metabolites. Thus, the plasma and brain glucose specific activities and the radioactivity of the acid metabolites present in brain were determined; from these values, glucose uptake into brain was estimated and brain glucose utilization
$\left(\mathrm{CMR}_{\text {glucose }}\right)$ determined $(17,18)$ :

Glucose uptake $(\mu \mathrm{mol} / 100 \mathrm{gm} / \mathrm{min})=$

Total metabolites in brain $(\mathrm{dpm} / \mathrm{g}) \times 100$

$\int$ plasma glucose specific activity $(\mathrm{dpm} / \mu \mathrm{mol}) \times \mathrm{dt}$

CMR glucose $(\mu \mathrm{mol} / 100 \mathrm{gm} / \mathrm{min})=$

Acid soluble metabolites in brain $(\mathrm{dpm} / \mathrm{g}) \times 100$

$\int$ plasma (or brain) glucose specific activity $(\mathrm{dpm} / \mu \mathrm{mol}) \times \mathrm{dt}$

Statistical methods for data analysis included the unpaired and paired Student's $t$ test and analysis of variants.

\section{RESULTS}

Blood metabolites. The subcutaneous injection of $0.1 \mathrm{ml} 50 \%$ glucose into 7-day postnatal rats resulted in an early hyperglycemia with peak blood glucose concentrations exceeding $200 \%$ of control (Fig. 1). Glucose remained high during the 1 st $\mathrm{h}$ of hypoxia and decreased thereafter toward the baseline level. As anticipated, hyperglycemia did not occur in the saline-treated (control) animals.

Blood lactate concentrations were not altered by either glucose or saline injection alone (Fig. 1). During hypoxia, lactate increased steadily in both groups but was always in greater concentrations in the glucose supplemented rats. Increases in blood pyruvate also occurred (not shown). There was an inverse relationship between lactate and pyruvate in the two groups, such

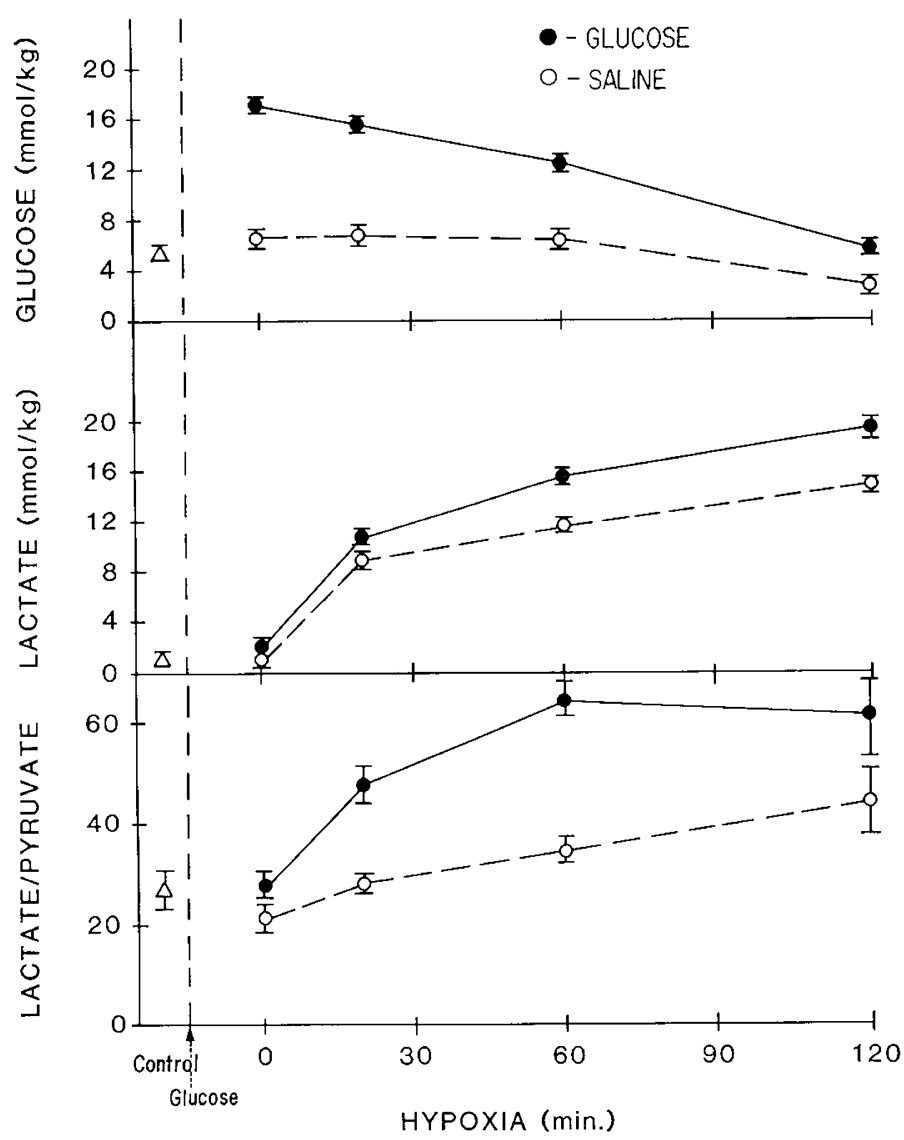

Fig. 1. Blood glucose, lactate, and lactate/pyruvate ratios in hyperglycemic and control immature rats during hypoxia. Seven-day postnatal rats received a subcutaneous injection of $0.1 \mathrm{ml}$ of either $50 \%$ glucose or normal saline, $15 \mathrm{~min}$ following which they were exposed to the hypoxia induced by the inhalation of $8 \%$ oxygen. Symbols represent means of four to six animals, vertical lines denote \pm 1 SEM. 
that lactate/pyruvate ratios were consistently lower in the control animals (Fig. 1).

Brain glycolytic intermediates. The hyperglycemia produced by glucose injection initially was associated with proportionate increases in glucose concentrations of both cerebral hemispheres despite the prior ligation of one common carotid artery (Fig. 2). However, significant decreases in tissue glucose were seen during hypoxia in both the glucose supplemented and control animals, with a better preservation of substrate concentrations in the contralateral hemisphere, especially of the glucose treated rat pups. Negligible levels $(<0.1 \mathrm{mmol} / \mathrm{kg})$ were present in the ipsilateral cerebral hemisphere of both glucose and saline treated animals by $2 \mathrm{~h}$ of hypoxia.

Alterations in brain lactate and pyruvate concentrations and in lactate/pyruvate ratios are shown in Table 1. Metabolite levels in the ipsilateral and contralateral cerebral hemispheres were little changed from control following common carotid artery ligation and the injection of either glucose or saline. During the Ist $\mathrm{h}$ of hypoxia, lactate ad pyruvate increased to similar degrees in the respective hemispheres in all animals studied, although concentrations tended to be higher in the ipsilateral hemisphere of the glucose-treated animals. By $2 \mathrm{~h}$ of hypoxia, brain lactate
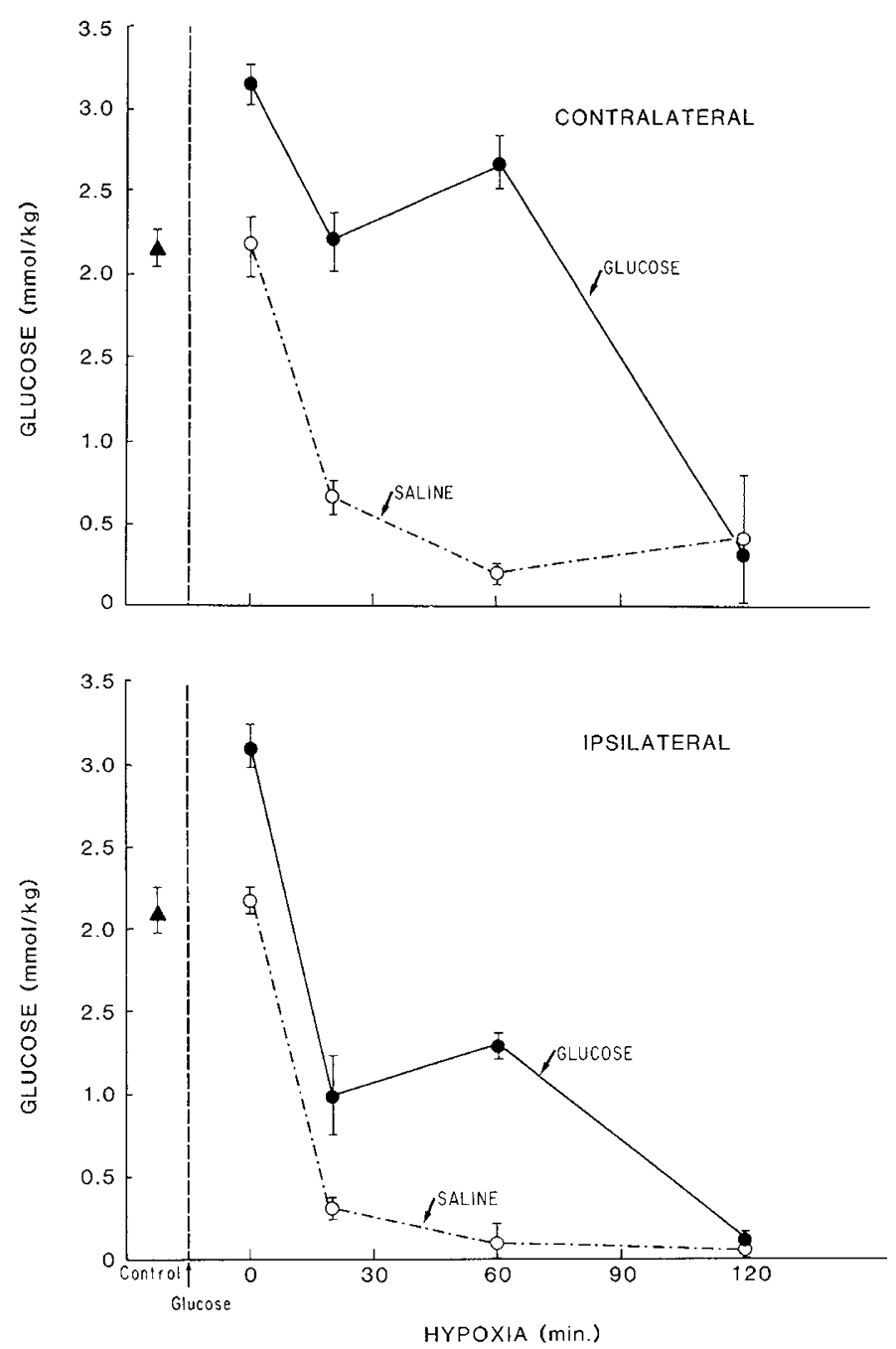

Fig. 2. Cerebral hemispheric glucose concentrations in glucose treated and control immature rats during hypoxia-ischemia. Seven-day postnatal rats underwent unilateral common carotid artery ligation following which they received a subcutaneous injection $(0.1 \mathrm{ml})$ of either $50 \%$ glucose or normal saline. Fifteen minutes later, the rat pups were subjected to hypoxia with $8 \%$ oxygen. Symbols represents means of four to seven animals either ipsilateral or contralateral to the common carotid artery occlusion; vertical lines denote \pm 1 SEM. was actually higher in the saline-treated animals, although the differences between the two groups were not significant $(p>$ $0.05)$.

Brain high-energy phosphate reserves. Cerebral hypoxia-ischemia was associated with major alterations in phosphocreatine and in the adenine nucleotides. In both glucose and saline treated rats, phosphocreatine in the ipsilateral cerebral hemisphere decreased immediately to approximately $25 \%$ of the control values, remained stable an additional $40 \mathrm{~min}$, and declined thereafter to near negligible levels at $2 \mathrm{~h}$ (Fig. 3). Similar, albeit less dramatic, changes in phosphocreatine were noted in the contralateral cerebral hemispheres (not shown).

Concentrations of the adenine nucleotides ATP, ADP, and AMP in glucose- and saline-supplemented rats are shown in Table 2 . The primary energy modulator, ATP, decreased during hypoxia-ischemia in the ipsilateral cerebral hemisphere of both groups of animals and was always lower in the saline-treated rat pups, although not significantly. By $2 \mathrm{~h}$ of hypoxia, ATP concentrations in both groups were less than $0.5 \mathrm{mmol} / \mathrm{kg}$.

Alterations in ADP and AMP of the ipsilateral cerebral hemisphere of both glucose- and saline-treated animals were such that the total adenine nucleotides (ATP + ADP + AMP) were partially depleted only at $2 \mathrm{~h}$ of hypoxia-ischemia. Although the reduction from control was greater in the saline-treated animals, the difference between the glucose and saline total adenine nucleotide values ( 1.53 versus $0.92 \mathrm{mmol} / \mathrm{kg}$ ) was not significant $(p>0.05)$. Minimal changes in ATP, ADP, and AMP occurred in the contralateral cerebral hemisphere of both glucose- and saline-treated animals when compared to alterations in the ipsilateral hemisphere (not shown).

Glucose uptake into and utilization by brain. The uptake of glucose into the brains of control 7-day-old rat pups averaged $21.6 \pm 1.6 \mu \mathrm{mol} / 100 \mathrm{~g} / \mathrm{min}$, while glucose utilization by brain averaged $7.4 \pm 1.3 \mu \mathrm{mol} / 100 \mathrm{~g} / \mathrm{min}$. These rates are approximately $1 / 10$ the respective rates for adult rat brain using the same technique (17). Cerebral glucose utilization in newborn rats equals $2.4 \mu \mathrm{mol} / 100 \mathrm{~g} / \mathrm{min}$ (19), $1 / 3$ the value for the 7 -day-old rat.

Brain glucose uptake and utilization were measured during the course of hypoxia-ischemia in glucose-supplemented rats and saline-treated controls. Glucose transport into brain of the hyperglycemic rat pups was always greater than that of the normoglycemia animals both prior to and during hypoxia (Fig. 4). Furthermore, glucose uptake into the cerebral hemisphere contralateral to the carotid artery occlusion was always greater during hypoxia than into the ipsilateral cerebral hemisphere either of the glucose- or saline-supplemented animals. Thus, the contralateral cerebral hemisphere of the glucose-treated animals exhibited the highest and the ipsilateral hemisphere of the salinetreated animals the lowest rate of glucose entry into brain.

Cerebral glucose utilization during hypoxia-ischemia is shown in Figure 5. Glucose consumption increased transiently only in the contralateral cerebral hemisphere of both the glucose- and saline-treated animals. In the ipsilateral cerebral hemisphere, glucose consumption was nearly identical in the two experimental groups and never increased above the control rate. Only at 2 $\mathrm{h}$ was glucose utilization in the saline-injected rat pups significantly lower than that of the glucose-treated animals $(p<0.05)$. However, total glucose consumption (the sum of the rates at 20 , 60 , and $120 \mathrm{~min}$ ) was not significantly different in two groups $(p>0.05)$.

\section{DISCUSSION}

That glucose supplementation of juvenile and adult animals accentuates hypoxic-ischemic brain damage is now well established in several species $(11-13,20)$. The pathophysiological mechanism by which glucose accentuates brain damage in adult animals has been related to excessive production of tissue lactic acid or to an associated derangement in $\mathrm{pH}$ homostasis (21-25). 
Table 1. Brain lactate, pyruvate, and lactate/pyruvate ratios in glurose-supplemented 7-day postnatal rats during hypoxiaischemia* $^{*}$

\begin{tabular}{|c|c|c|c|c|c|c|}
\hline \multirow{2}{*}{$\begin{array}{l}\text { Experimental } \\
\text { manipulation }\end{array}$} & \multicolumn{3}{|c|}{ Ipsilateral } & \multicolumn{3}{|c|}{ Contralateral } \\
\hline & Lactate & Pyruvate & $\mathrm{L} / \mathrm{P}$ & Lactate & Pyruvate & $\mathrm{L} / \mathrm{P}$ \\
\hline Control & $0.54 \pm 0.11$ & $0.09 \pm 0.01$ & $6.2 \pm 0.9$ & $0.70 \pm 0.17$ & $0.09 \pm 0.02$ & $8.3 \pm 1.7$ \\
\hline $\begin{array}{l}\text { Ligation }+ \text { hypoxia }+ \\
\text { Glucose }(0 \mathrm{~min}) \\
\text { Saline }(0 \mathrm{~min})\end{array}$ & $\begin{array}{l}0.78 \pm 0.21 \\
1.00 \pm 0.20\end{array}$ & $\begin{array}{l}0.09 \pm 0.01 \\
0.10 \pm 0.01\end{array}$ & $\begin{array}{r}8.1 \pm 1.8 \\
10.3 \pm 1.9\end{array}$ & $\begin{array}{l}0.67 \pm 0.08 \\
0.71 \pm 0.13\end{array}$ & $\begin{array}{l}0.10 \pm 0.01 \\
0.07 \pm 0.01\end{array}$ & $\begin{array}{l}7.0 \pm 0.4 \\
9.6 \pm 1.7\end{array}$ \\
\hline $\begin{array}{l}\text { Glucose }(20 \mathrm{~min}) \\
\text { Saline }(20 \mathrm{~min})\end{array}$ & $\begin{array}{l}13.10 \pm 0.90 \dagger \\
10.90 \pm 0.40 \dagger\end{array}$ & $\begin{array}{l}0.24 \pm 0.03 \dagger \\
0.17 \pm 0.03 \dagger\end{array}$ & $\begin{array}{l}55.0 \pm 4.4 \dagger \ddagger \\
78.1 \pm 17.5 \dagger\end{array}$ & $\begin{array}{l}9.90 \pm 0.40 \dagger \\
9.20 \pm 0.30 \dagger\end{array}$ & $\begin{array}{l}0.23 \pm 0.03 \dagger \\
0.25 \pm 0.02 \dagger\end{array}$ & $\begin{array}{l}43.1 \pm 1.8 \dagger \\
38.9 \pm 4.5 \dagger\end{array}$ \\
\hline $\begin{array}{l}\text { Glucose }(60 \mathrm{~min}) \\
\text { Saline }(60 \mathrm{~min})\end{array}$ & $\begin{array}{l}16.30 \pm 0.80 \dagger \dagger \\
12.20 \pm 0.30 \dagger\end{array}$ & $\begin{array}{l}0.32 \pm 0.02 \dagger \\
0.21 \pm 0.04 \dagger\end{array}$ & $\begin{array}{l}51.8 \pm 1.4 \dagger \ddagger \\
65.9 \pm 12.0 \dagger\end{array}$ & $\begin{array}{l}12.30 \pm 0.60 \dagger \\
11.90 \pm 0.90 \dagger\end{array}$ & $\begin{array}{l}0.29 \pm 0.01 \dagger \\
0.26 \pm 0.03 \dagger\end{array}$ & $\begin{array}{l}42.1 \pm 0.6 \dagger \\
45.2 \pm 6.0 \dagger\end{array}$ \\
\hline $\begin{array}{l}\text { Glucose }(120 \mathrm{~min}) \\
\text { Saline }(120 \mathrm{~min})\end{array}$ & $\begin{array}{l}14.80 \pm 2.30 \dagger \\
18.90 \pm 5.70 \dagger\end{array}$ & $\begin{array}{l}0.14 \pm 0.04 \dagger \\
0.11 \pm 0.03 \dagger\end{array}$ & $\begin{array}{l}130.0 \pm 32.0 \dagger \\
16.0 \pm 11.0 \dagger\end{array}$ & $\begin{array}{l}12.40 \pm 1.70 \dagger \\
15.80 \pm 2.00 \dagger\end{array}$ & $\begin{array}{l}0.28 \pm 0.07 \dagger \\
0.19 \pm 0.06 \dagger\end{array}$ & $\begin{aligned} 63.2 & \pm 26.0 \dagger \\
107.0 & \pm 41.6 \dagger\end{aligned}$ \\
\hline
\end{tabular}

* Values represent means $\pm 1 \mathrm{SE}$ in $\mathrm{mmol} / \mathrm{kg}$ brain wet weight of four to seven animals from separate litters. Glucose or saline was administered to the animals $15 \mathrm{~min}$ prior to sacrifice $(0 \mathrm{~min})$ or to onset of hypoxia. All animals, including controls, underwent unilateral common carotid artery ligation 4 hours prior to exposure to hypoxia.

$\dagger p<0.001$ compared to control.

$\ddagger p<0.05$ compared to ipsilateral saline at the same interval of hypoxia. No statistically significant differences were noted when ipsilateral and contralateral lactate and pyruvate levels and lactate/pyruvate (L/P) ratios were compared in either glucose- or saline-treated animals.

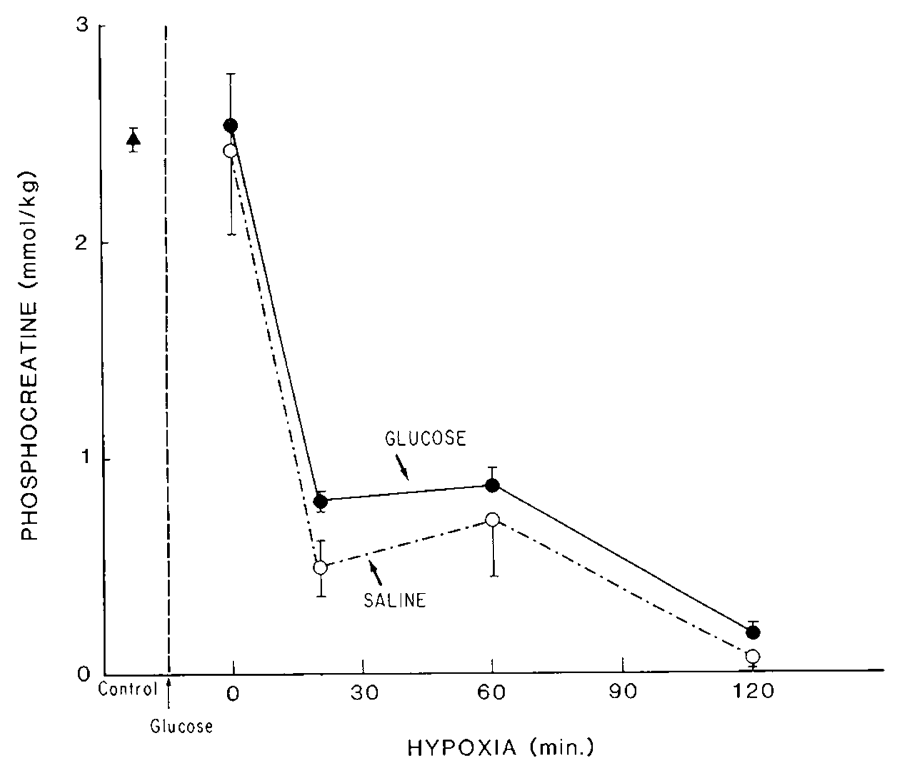

Fig. 3. Cerebral hemispheric phosphocreatine concentrations in glucose-treated and control immature rats during hypoxia-ischemia. The animals were prepared as described in Figure 2. Symbols represent means of four to seven animals for the cerebral hemisphere ipsilateral to the common carotid artery ligation; vertical lines denote \pm 1 SEM.

Some investigators have suggested that brain lactacidosis enhances hypoxic-ischemic injury in vulnerable structures and that a minimum concentration of $20 \mathrm{mmol}$ lactate $/ \mathrm{kg}$ brain weight is required for irreversible damage to occur $(21,24)$. Presumably, excessive lactate production during hyperglycemic cerebral hypoxia-ischemia results from a greater acceleration of anaerobic glycolytic flux than that which occurs when the circulating glucose concentration is not increased. However, it has yet to be demonstrated in adult animals that hyperglycemia per se increases cerebral glucose consumption via the glycolytic pathway with or without superimposed hypoxia-ischemia.

We previously have shown that, unlike adult animals, glucose supplementation of immature rats does not lead to accentuated hypoxic-ischemic brain damage (8). The metabolic perturbations occurring in brain of hyperglycemic rat pups during hypoxiaischemia readily explain this age-specific difference in neuropathological outcome. Thus, glucose in the cerebral hemisphere ipsilateral to the common carotid artery occlusion declined immediately in both glucose- and saline-treated animals to negligible levels by $2 \mathrm{~h}$ of hypoxia. Elevations in lactate and pyruvate and in lactate/pyruvate ratios also were comparable in the two groups. Decreases in glucose combined with the increases in lactate and pyruvate indicate an acceleration of anaerobic glycolytic flux in response to hypoxia-ischemia. That anaerobic metabolism was enhanced to an equal degree in the glucose- and saline-treated rats is supported by the finding of similar rates of glucose utilization in the two groups. Given the fact that anaerobic glycolysis is an inefficient mechanism to maintain tissue energy balance, it is not surprising that the cerebral energy reserves, ATP and phosphocreatine, declined to low levels by the terminus of hypoxia. Thus, it appears that glucose delivery to the immature brain contributes little to its metabolism even during hyperglycemia, owing presumably to the low transport capacity of the immature blood-brain barrier for glucose (26) as well as to low activity of the glucose phosphorylating enzyme, hexokinase (27), both of which are rate-limiting for glucose utilization. This conclusion emphasizes the critical role of endogenous stores of carbohydrate (glycogen and glucose) for energy production via glycolysis during hypoxia-ischemia $(28,29)$.

In the present investigation, lactate concentrations were increased to a similar extent in the ipsilateral and contralateral cerebral hemispheres of both glucose-supplemented and control rats undergoing hypoxia-ischemia (see Table 1). The relative uniformity of lactate accumulation in the two cerebral hemispheres, only one of which will ultimately show ischemic damage, suggests that lactic acid per se is not the primary factor causing tissue injury. In the present model of cerebral hypoxia-ischemia in the immature rat, widespread infarction and edema occur in the ischemic hemisphere $(8,14)$, although lactate concentrations rarely exceeded $20 \mathrm{mmol} / \mathrm{kg}$ (see Table 1), a presumed threshold value for damage to occur in adult brain $(21,24)$. Furthermore, lactate in the ischemic hemisphere never exceeded by more than $4 \mathrm{mmol} / \mathrm{kg}$ the accumulated lactate in the nonischemic contralateral cerebral hemisphere, and the difference between the two sides was usually $<2 \mathrm{mmol} / \mathrm{kg}$. Studies by other investigators have prompted a similar conclusion that lactic acid alone is not the sole determinant of brain tissue damage $(23,30)$. 
Table 2. High-energy phosphate reserves in ipsilateral cerebral cortex of glucose-supplemented 7-day postnatal rats during hypoxiaischemia*

\begin{tabular}{|c|c|c|c|c|}
\hline $\begin{array}{l}\text { Experimental } \\
\text { manipulation }\end{array}$ & ATP & ADP & AMP & $\mathrm{ATP}+\mathrm{ADP}+\mathrm{AMP}$ \\
\hline Control & $2.2 \pm 0.04$ & $0.34 \pm 0.04$ & $0.04 \pm 0.01$ & $2.59 \pm 0.01$ \\
\hline $\begin{array}{l}\text { Ligation }+ \text { hypoxia }+ \\
\text { Glucose }(0 \mathrm{~min}) \\
\text { Saline }(0 \mathrm{~min})\end{array}$ & $\begin{array}{l}2.22 \pm 0.01 \\
2.34 \pm 0.04\end{array}$ & $\begin{array}{l}0.34 \pm 0.03 \\
0.39 \pm 0.03\end{array}$ & $\begin{array}{l}0.04 \pm 0.01 \\
0.03 \pm 0.01\end{array}$ & $\begin{array}{l}2.61 \pm 0.10 \\
2.76 \pm 0.04\end{array}$ \\
\hline $\begin{array}{l}\text { Glucose }(20 \mathrm{~min}) \\
\text { Saline }(20 \mathrm{~min})\end{array}$ & $\begin{array}{l}1.67 \pm 0.03 \dagger \\
1.15 \pm 0.34 \dagger\end{array}$ & $\begin{array}{l}0.68 \pm 0.04 \dagger \\
0.61 \pm 0.06 \dagger\end{array}$ & $\begin{array}{l}0.19 \pm 0.01 \dagger, \ddagger \\
0.72 \pm 0.28 \dagger\end{array}$ & $\begin{array}{l}2.54 \pm 0.02 \\
2.48 \pm 0.13\end{array}$ \\
\hline $\begin{array}{l}\text { Glucose }(60 \mathrm{~min}) \\
\text { Saline }(60 \mathrm{~min})\end{array}$ & $\begin{array}{l}1.58 \pm 0.05 \dagger \\
1.28 \pm 0.12 \dagger\end{array}$ & $\begin{array}{l}0.58 \pm 0.01 \dagger \\
0.60 \pm 0.04 \dagger\end{array}$ & $\begin{array}{l}0.10 \pm 0.01 \dagger \\
0.40 \pm 0.18 \dagger\end{array}$ & $\begin{array}{l}2.26 \pm 0.03 \\
2.28 \pm 0.34\end{array}$ \\
\hline $\begin{array}{l}\text { Glucose }(120 \mathrm{~min}) \\
\text { Saline }(120 \mathrm{~min})\end{array}$ & $\begin{array}{l}0.41 \pm 0.14 \dagger \\
0.10 \pm 0.04 \dagger\end{array}$ & $\begin{array}{l}0.39 \pm 0.05 \ddagger \\
0.22 \pm 0.02\end{array}$ & $\begin{array}{l}0.73 \pm 0.11 \dagger \\
0.60 \pm 0.14 \dagger\end{array}$ & $\begin{array}{l}1.53 \pm 0.19 \dagger \\
0.92 \pm 0.16 \dagger\end{array}$ \\
\hline
\end{tabular}

* Values represent means $\pm 1 \mathrm{SE}$ in $\mathrm{mmol} / \mathrm{kg}$ brain wet weight of four to seven animals from separate litters. Glucose or saline was administered to the animals $15 \mathrm{~min}$ prior to sacrifice $(0 \mathrm{~min})$ or to onset of hypoxia. All animals, including controls, underwent unilateral common carotid artery ligation $4 \mathrm{~h}$ prior to exposure to hypoxia.

$\dagger p<0.05$ compared to control.

$\ddagger p<0.05$ compared to saline at the same interval of hypoxia.

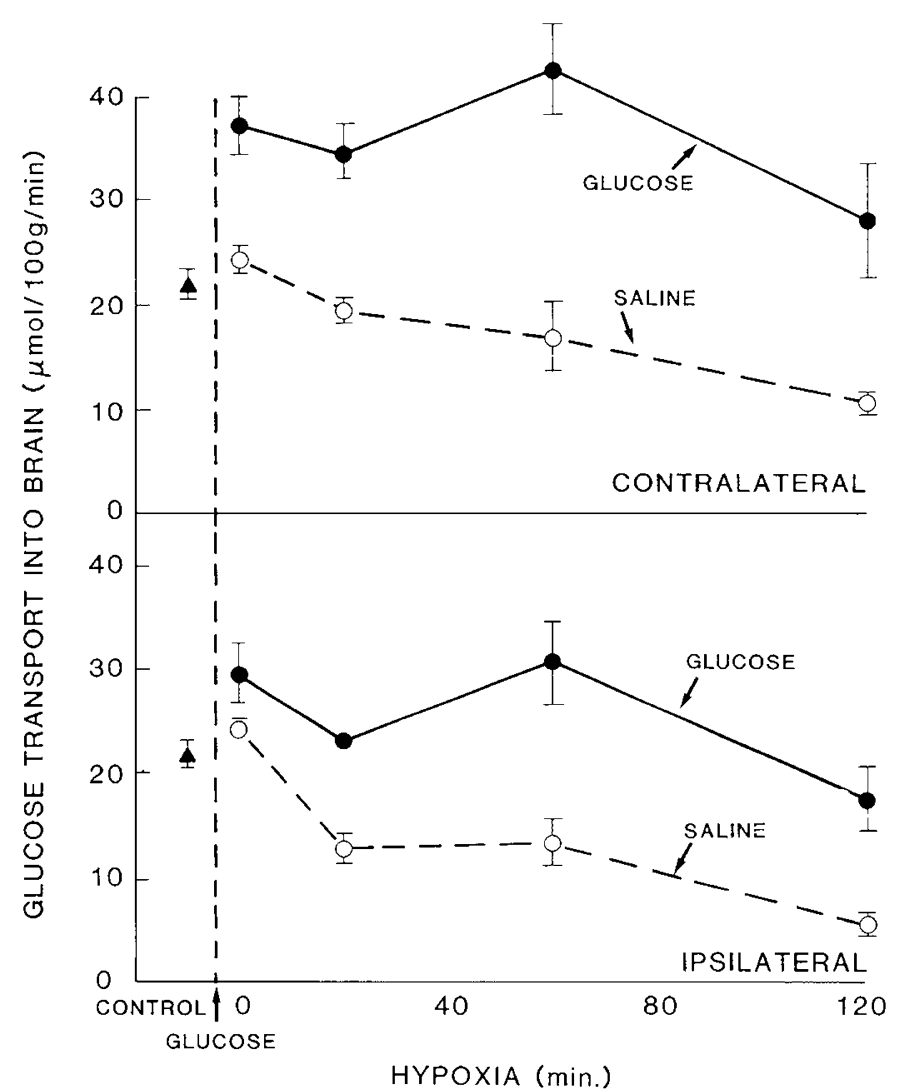

Fig. 4. Glucose transport into brains of glucose-treated and control immature rats during hypoxia-ischemia. Seven-day postnatal rats were exposed to hypoxia-ischemia as described in Figure 2, during which they received a subcutaneous injection of $2.5 \mu \mathrm{Ci} 2-\left[{ }^{14} \mathrm{C}\right]$-glucose. Symbols represent means of five to seven animals either ipsilateral or contralateral to the common carotid artery occlusion; vertical lines denote \pm 1 SEM.

Certain clinical implications are inherent in the present experimental study. Thus, the data suggest that physicians need not restrict or curtail glucose administration to an acutely asphyxiated fetus or newborn infant for fear of accentuating brain

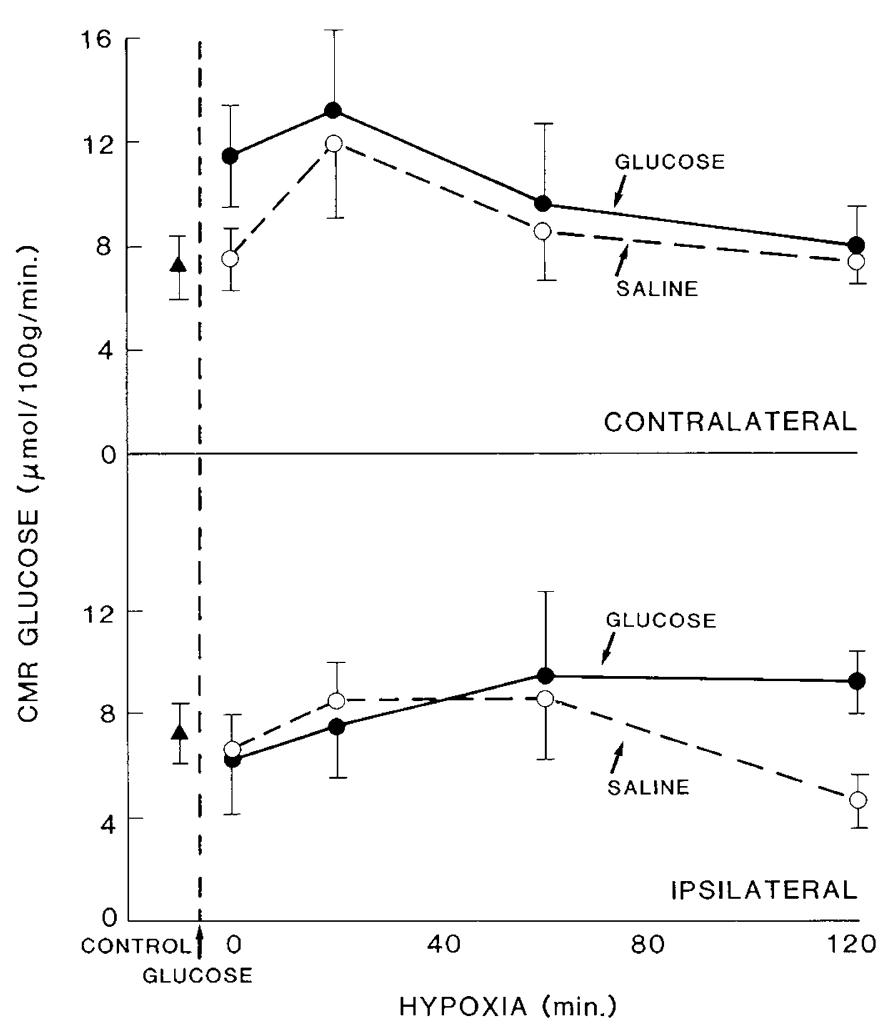

Fig. 5. Cerebral glucose utilization (CMRglucose) in glucose-treated and control immature rats during hypoxia-ischemia. The animals were prepared according to the procedures described in Figures 2 and 4. Symbols represent means of five to seven animals either ipsilateral or contralateral to the common carotid artery occlusion; vertical lines denote \pm 1 SEM.

damage. On the contrary, maternal glucose supplementation during labor might prolong central respiratory drive and minimize cardiovascular depression with its attendant hypotension and secondary cerebral ischemia (4-8). The relative preservation of respiratory and cardiovascular function, in turn, should reduce the need for extensive resuscitation at birth. In this regard, clinical 
investigations have shown that the better the Apgar score at birth, the more favorable the ultimate neurological outcome $(3,31$, 32). A controlled clinical trial of glucose supplementation in mothers at risk for delivering an asphyxiated infant seems warranted to clarify the role of glucose in perinatal cerebral hypoxiaischemia.

\section{REFERENCES}

1. Dweck HS, Cassady G 1974 Glucose intolerance in infants of very low birth weight. Pediatrics 53:189-195

2. Monaco M, Copen P, Bloom E, Carter A, Vannucci R 1978 Cerebrospinal fluid/blood glucose ratios in premature and full-term infants. Pediatr Res $12: 554$

3. Volpe JJ 1981 Neurology of the Newborn. WB Saunders, Philadelphia, pp $180-238$

4. Himwich HE, Bernstein AO, Herrlich H, Chester A, Fazekas JF 1942 Mechanisms for the maintenance of life in the newborn during anoxia. Am $J$ Physiol 135:387-391

5. Britton SW, Kline RF 1945 Age, sex, carbohydrate, adrenal cortex and other factors in anoxia. Am J Physiol 145:190-202

6. Stafford A, Weatherall JAC 1960 The survival of young rats in nitrogen. J Physiol 153:457-472

7. Holowach-Thurston J, Hauhart RE, Jones EM 1974 Anoxia in mice: reduced glucose in brain with normal or elevated glucose in plasma and increased survival after glucose treatment. Pediatr Res 8:238-243

8. Voorhies TE, Rawlinson D, Vannucci RC 1986 Glucose and perinatal hypoxicischemic brain damage. Neurology 36:1115-1118.

9. Dawes GS, Mott JC. Shelley HJ 1959 The importance of cardiac glycogen for the maintenance of life in fetal lambs and newborn animals during anoxia. J Physiol 146:516-538

10. Dawes GS, Jacobson HN, Mott JC, Shelley HJ, Stafford A 1963 The treatment of asphyxiated mature foetal lambs and rhesus monkeys with intravenous glucose and sodium carbonate. J Physiol 169:167-173

11. Myers RE, Yamaguchi S 1977 Nervous system effects of cardiac arrest in monkeys. Arch Neurol 34:65-74

12. Kalimo H, Rehncrona S, Soderfeldt B, Olsson Y, Siesjö BK 1981 Brain lactic acidosis and ischemic cell damage: II. Histopathology. J Cereb Blood Flow Metabol 1.313-327

13. Pulsinelli WA, Waldman S, Rawlinson D, Plum F 1982 Moderate hyperglycemia augments ischemic brain damage: a neuropathological study in the rat. Neurology 32:1239-1246

14. Rice JE Vannucci RC, Brierley JB 1981 The influence of immaturity on hypoxic-ischemic brain damage in the rat. Ann Neurol 9:131-141
15. Vannucci RC, Duffy TE 1974 The influence of birth on carbohydrate and energy metabolism in rat brain. Am J Physiol 226:933-940

16. Lowry OH, Passoneau JV 1972 A Flexible System of Enzymatic Analysis. Academic Press, New York

17. Hawkins RA, Miller AL, Cremer JE, Veech RL 1974 Measurement of the rate of glucose utilization by rat brain in vivo. J Neurochem 23:917-923

18. Miller AL, Corddry DH 1981 Brain carbohydrate metabolism in developing rats during hypercapnia. J Neurochem 36:1202-1210

19. Moore TJ, Lione AP, Regen DM, Tarpley HL, Raines PL 1971 Brain glucose metabolism in the newborn rat. Am J Physiol 221:1746-1753

20. DeCourten-Myers GM, Yamaguchi S, Myers RE 1982 Accentuation of hypoxic-ischemic brain injury by post-exposure infusion of glucose solutions. Neurology 32:21

21. Myers RE 1979 A unitary therapy of causation of anoxic and hypoxic brain pathology. In: Fahn S, David J Rowland L (eds) Cerebral Hypoxic and its Consequences. Raven Press, New York, pp 195-213

22. Rehncrona S, Rosen I, Siesjö BK 1980 Excessive cellular acidosis: an important mechanism of neuronal damage in the brain? Acta Physiol Scand 110:435437

23. Welsh RA, Ginsberg MD, Rieder W, Budd WW 1980 Deleterious effect of glucose pretreatment on recovery from diffuse cerebral ischemia in the cat: II. Regional metabolite levels. Stroke 11:355-363

24. Rehncrona S, Rosen I, Siesjö BK 1981 Brain lactic acidosis and ischemic cell damage: I. Biochemistry and neurophysiology. J Cereb Blood Flow Metabol 1:297-311

25. Gardiner M, Smith M, Kagstrom E 1982 Influence of blood glucose concentration on brain lactate accumulation during severe hypoxia and subsequent recovery of brain energy metabolism. J Cereb Blood Flow Metabol 2:429_ 438

26. Cremer JE, Cunningham VJ, Pardridge WM 1979 Kinetics of blood-brain barrier transport of pyruvate, lactate and glucose in suckling, weaning and adult rats. J Neurochem 33:439

27. Booth RF, Patel TB, Clark JM 1980 The development of enzymes of energy metabolism in the brain of a precocial (guinea pig) and non-precocial (rat) species. J Neurochem 34:17-25

28. Vannucci RC, Duffy TE 1976 Carbohydrate metabolism in fetal and neonatal rat brain during anoxia and recovery. Am J Physiol 230:1259-1265

29. Vannucci RC, Vannucci SJ 1980 Glycogen metabolism during anoxia and recovery in newborn rat brain. J Neurochem 34:1100-1105

30. Pulsinelli WA, French J, Rawlinson D, Plum F 1982 Cerebral ischemia damages neurons despite lowered brain lactate levels. Ann Neurol 12:86

31. Scott H 1976 Outcome of very severe birth asphyxia. Arch Dis Child 51:712718

32. Nelson KB, Ellenberg JH 1981 Apgar scores of predictors of chronic neurologic disability. Pediatrics $68: 36-44$. 